Научная статья

УДК 687.1

DOI https://doi.org/10.24866/VVSU/2073-3984/2021-4/167-176

М.А. Гусева ${ }^{1}$

Е.Г. Андреева ${ }^{2}$

И.Б. Разин ${ }^{3}$

И. Д. уссев $^{4}$

Российский государственный университет им. А.Н. Косыгина (Технологии. Дизайн. Искусство) Москва. Россия

\title{
Трехмерная графика параметрического проектирования цифровых двойников швейных изделий простых форм
}

Аннотация. В период восстановительного лечения после травм ног человек, наряду с ограничением мобильности, испытывает трудности в подборе предметов гардероба. Программами реабилитации рекомендуется ношение внешних фиксаторов, позиционирующих в требуемой конфигурации участки костно-мышечного аппарата. Внешние фиксаторы представляют собой разнообразные конструкции, включающие ребра жесткости из металлических или композитных материалов. Пространственная конфигурация фиксирующих устройств и длительность их эксплуатации зависят от тяжести заболеваний. Внешние фиксаторы изменяют габариты ног, поэтому многие пациенты на период лечения обновляют свой гардероб поясной одежды и обуви изделиями больших размеров. Кроме того, эксплуатация такого устройства, как аппарат

${ }^{1}$ Гусева Марина Анатольевна - канд. техн. наук, доцент, доцент кафедры художественного моделирования, конструирования и технологии швейных изделий. ORCID: https://orcid.org/0000-0003-3491-6132; e-mail: guseva_marina67@mail.ru

2 Андреева Елена Георгиевна - д-р техн. наук, профессор, профессор кафедры художественного моделирования, конструирования и технологии швейных изделий. ORCID: https://orcid.org/0000-0002-1464-0450; e-mail: elenwise@mail.ru

3 Разин Игорь Борисович - канд. техн. наук, доцент, зав. кафедрой информационных технологий. ORCID: https://orcid.org/0000-0002-6481-0008; e-mail: igor-razin@ yandex.ru

${ }^{4}$ Гусев Иван Дмитриевич - магистрант кафедры информационных технологий. ORCID: https://orcid.org/0000-0002-4237-484X; e-mail: gusev_ivan97@mail.ru 
Илизарова, сопровождается ношением специальных швейных изделий - чехлов для ног, защищающих поврежденный участок ноги от воздействий окружающей среды. Композиционно-конструктивное решение типовых моделей чехлов для ног очень простое. Исследованием установлено, что в обществе присутствует многочисленная группа потребителей, предпочитающих индивидуальность образа в период восстановительного лечения. Высокая степень востребованности персонифицированных моделей швейных изделий реабилитационного ассортимента определила представляемые в статье исследования. Авторами разработана и апробирована методика проектирования пространственной формы швейных чехлов для ног в параметрической графической САПР. Входными параметрами для трехмерного конструирования изделий являются 3D скан-образы цифровых моделей ног и особенности пространственной конфигурации внешних фиксаторов. В статье представлены общие положения исследуемой научной темы на примере проектирования реабилитационных чехлов на аппарат Илизарова.

Ключевые слова: цифровые двойники фигур, оценка внешнего вида, реабилитационные изделия, 3D параметрическое проектирование.

M.A. Guseva

E.G. Andreeva

I.B. Razin

I.D. Gusev

The Kosygin State University of Russia

Moscow. Russia

\section{Three-dimensional graphics of parametric design of digital twins of garments of simple shapes}

Abstract. During the period of rehabilitation after leg injuries, a person, along with limited mobility, experiences difficulties in the selection of wardrobe items. Rehabilitation programs recommend wearing external fixators positioning the parts of the musculoskeletal system in the desired configuration. External anchors are a variety of designs that include stiffeners made of metal or composite materials. The spatial configuration of the fixation devices and the duration of their operation depend on the severity of the disease. External fixators change the dimensions of the legs; therefore, many patients for the period of treatment update their wardrobe of waist clothes and shoes for large-sized items. In addition, the operation of devices such as the llizarov apparatus is accompanied by the wearing of special garments - foot covers that protect the damaged leg area from environmental influences. The compositional and constructive solution of typical models of foot covers is very simple. The study found that in society there is a large group of consumers who prefer the individuality of the image during the period of rehabilitation treatment. The high degree of demand for personalized models of garments of the rehabilitation assortment determined the studies presented in the article. The authors have developed and tested a methodology for designing the spatial shape of sewing foot covers in parametric graphic CAD. Input parameters for three-dimensional design of products are 3D scan images of digital leg models and features of 
М.А. Гусева и др. Трехмерная графика параметрического проектирования цифровых двойников...

the spatial configuration of external fixators. The article presents the general provisions of the research topic under study on the example of designing rehabilitation covers for the llizarov apparatus.

Keywords: digital twins of figures, assessment of appearance, rehabilitation products, 3D parametric design.

\section{Введение}

Ежегодно свыше $9 \%$ населения России подвержены травмам ног (переломы различной степени тяжести, повреждения суставных связок, вывихи) и обострениям воспалительных дегенеративных заболеваний суставов ног (синовиты, артриты) [1]. Периоды травмы и последующего восстановления пациенты проходят в состоянии малой мобильности, течение которого часто сопровождает физический и психологический шок. У многих нарушение целостности тела вызывает поведенческие нарушения и неврозы [2]. Сложность физического постоперационного состояния пациентов отягощена длительным отсутствием функциональной нагрузки на костно-мышечный аппарат поврежденной конечности, наличием массивных повязок из гипса или громоздких внешних фиксаторов для анатомического сопоставления и обездвиживания отломков костей. Для выраженной мотивации на здоровье и устранение последствий стрессового состояния клинические психологи советуют пациентам проявлять различные способы творческого приспособления к реальности [3], к числу которых относится шопинг и совершенствование внешнего облика обновлением гардероба. Особенности функционирования организма в посттравматический восстановительный период оказывают влияние на предпочтения человеком новых швейных изделий. Потребители останавливают свой выбор на комфортных, не ограничивающих динамику моделях $[4,5]$, что в итоге помогает социальной интеграции субъектов и скорейшему возвращению в трудовую деятельность [6].

Мониторингом целевой аудитории, проведенным среди пациентов травматологических отделений, членов их семей, соцработников и медперсонала, установлено, что с момента выписки из лечебного заведения многие больные задумываются о приобретении специальных швейных изделий реабилитационной направленности - чехлов для ног, маскирующих установленные на конечностях фиксаторы [7]. Кроме того, громоздкость фиксирующих конструкций вынуждает людей приобретать новую одежду, так как изделия привычных размеров не соответствуют пространственным очертаниям фигуры.

Подавляющее большинство коммуникаций современного мира организовано для самостоятельно передвигающихся людей, поэтому приобретенная в результате физической травмы маломобильность вынуждает человека перестраиваться и адаптироваться к новым условиям. Специальные швейные чехлы для ног предназначены для инклюзии травмированного человека в социум. Чехлы для ног - это инновационный продукт, которому еще предстоит освоение рынка. Поэтому расширение ассортимента швейных реабилитационных изделий инновационными моделями направлено не только на развитие потенциала индуст- 
рии, но и на формирование у целевых потребителей позитивной жизненной позиции в соответствии с принципами «теории-экстрабилити» [8].

Целью исследования является анализ ассортимента реабилитационных швейных чехлов для ног на аппараты внешней фиксации, систематизация композиционно-конструктивных решений изделий для процесса трехмерного проектирования конструкций в среде параметрических САПР с визуализацией образа.

\section{Основная часть}

Программами лечения и реабилитации после травм ног предусмотрено длительное ношение пациентами разнообразных по форме и конструктивнотехнологическому решению внешних фиксаторов для стабилизации положения капсульно-связочного аппарата поврежденных суставов и позиционирования фрагментов костной системы. Анализ ассортимента внешних фиксаторов, представленных на специализированных торговых площадках, показал, что наиболее громоздкими габаритами обладают изделия, включающие ребра жесткости [9]. К моделям фиксирующих устройств, увеличивающих обхватные размеры ног в средней степени, относятся: брейсы (рис. 1a), армированные наколенники (рис. 1б) и ортезы с измеряемыми углами (рис. 1в). К внешним фиксаторам крупных размеров относятся: деротационные ортезы (рис. 1г), ортезы с боковыми шинами для фиксирования угловых положений (рис. 1д), аппарат Илизарова (рис. 1е).

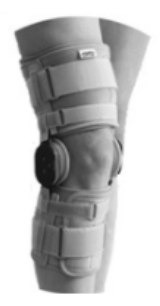

a

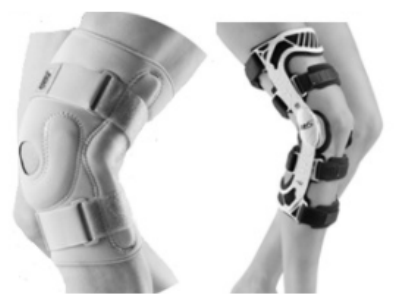

6

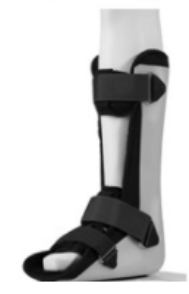

$\Gamma$

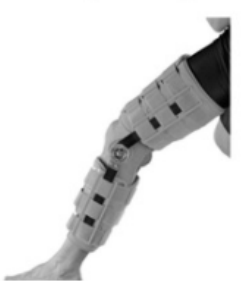

д

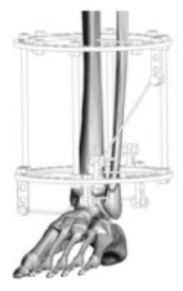

e

Рис. 1. Внешние фиксаторы с ребрами жесткости: а - брейс с гильзами;

б - ортез-наколенник с металлическими шарнирами; в - ортез с полицентрическими шарнирами; г - деротационный ортез на голеностопный сустав; д - ортез с боковыми шинами на коленный сустав [10]; е - аппарат Илизарова на голень [11]

Ношение внешних фиксаторов снижает нагрузку на костно-мышечную систему организма человека, способствует скорейшему началу двигательной активности и восстановлению после травмы. Поэтому после выписки из стационара многие пациенты сталкиваются с проблемой несоответствия габаритов одежды из личного гардероба новым внешним очертаниям травмированных конечностей. Интересен опыт швейного предприятия АРСАНА (г. Курган) [12], сотрудничающего с медицинским центром, специализирующимся на лечении сложных переломов способом установки чрескостного компрессионно-дистракционного аппарата [11]. Пациентам с установленным аппаратом Илизарова еще в стационаре предлагают приобрести надеваемые поверх фиксаторов [13] специальные чехлы, основное назначение которых - минимизация негативных воздействий 
М.А. Гусева и др. Трехмерная графика параметрического проектирования цифровых двойников...

окружающей среды (грязи, холода, влажности, ветра и т.д.) на травмированный участок ноги. Анализ ассортимента и композиционно-конструктивного решения моделей чехлов, выпускаемых предприятием АРСАНА, показал, что это объемные изделия простых геометрических форм - цилиндра или конуса (рис. 2). Фирма выпускает модели в вариациях по: 1) длине чехла; 2) длине и ширине подошвы; 3) окружности верхнего кольца аппарата Илизарова [11].
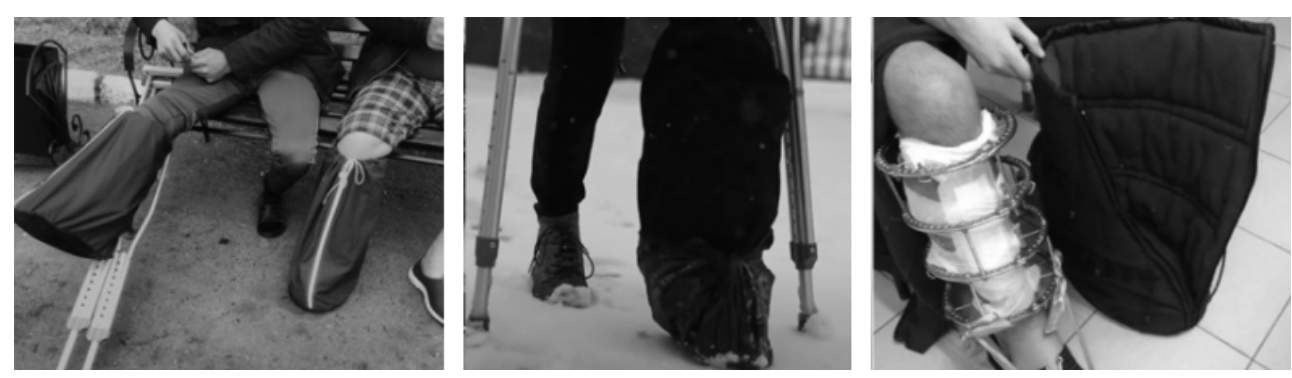

Рис. 2. Типовые модели межсезонных чехлов на аппарат внешней фиксации

Входная информация, запрашиваемая предприятием АРСАНА у клиентов, включает также опции сезонности изделия и желаемого конфекцион-пакета (рис. 3). Недостатком оформления сайта является отсутствие информации о внешнем виде готового швейного изделия. Потребители не получают визуальной характеристики модели как в опосредованной подаче, так и в образе, надетом на внешний фиксатор, что, на наш взгляд, снижает результативность бизнеспроекта.

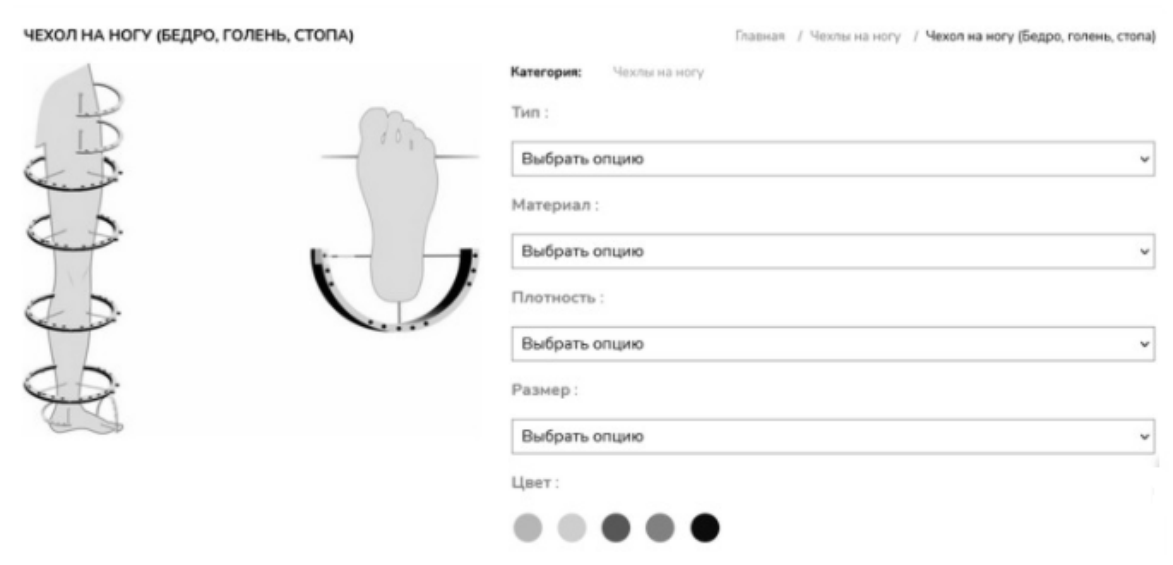

Рис. 3. Фрагмент страницы сайта АРСАНА

Важным потребительским свойством реабилитационных чехлов для ног является минимизация психогенных последствий травмы, поэтому целесообразно представлять клиентам изображение реабилитационного швейного изделия в виде цифрового клона во избежание ассоциаций со своей персоной. 
Современные трехмерные графические системы включают модули визуализации пространственной конфигурации объектов проектирования. Для достоверности конструкторских решений проектировщики часто используют в качестве входной информации [14] скан-копии трехмерных объектов [15], являющихся основой для позиционирования трехмерной оболочки проектируемого швейного изделия [16]. В качестве программной среды для экспериментального проектирования цифровой модели чехла на аппарат внешней фиксации выбраны CAПP Rhinoceros 3D (с интегрированным плагином Grasshopper) и CLO3D (симулятор примерок швейных изделий). Анализ инструментария показал, что трехмерная графическая информация, сохраненная в формате.obj, импортируется в среду выбранных программ [17]. Авторами проведены антропометрические исследования для формирования скан-образа ног человека. 3D аватар сформирован сканированием субъекта 3D сенсором Artec 3D Eva (рис. 4a). Выбранный способ антропометрии актуален при исследовании телосложения маломобильных потребителей, поскольку является наименее травматичным, как физически, так и психологически [18]. После удаления графических «шумов» и сглаживания контуров полученная пространственная модель цифровых ног импортируется в среду CAПP Rhinoceros 3D для извлечения размерных характеристик и последующей параметризации (рис. 4б). Инструментами графики по поверхности аватара нанесены линии измерений в соответствии с методикой антропометрии [17]. Программированием в плагине Grasshopper заданы зависимости (рис. 4в), позволяющие автоматически получить новые конфигурации оболочек аватаров [19] при изменении одной/нескольких антропометрических характеристик.

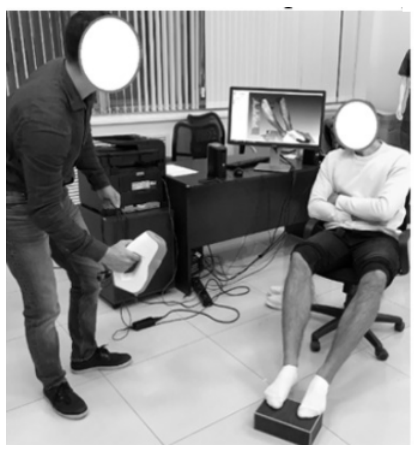

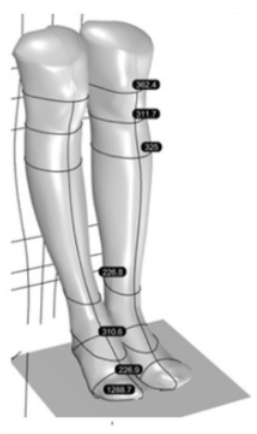

б

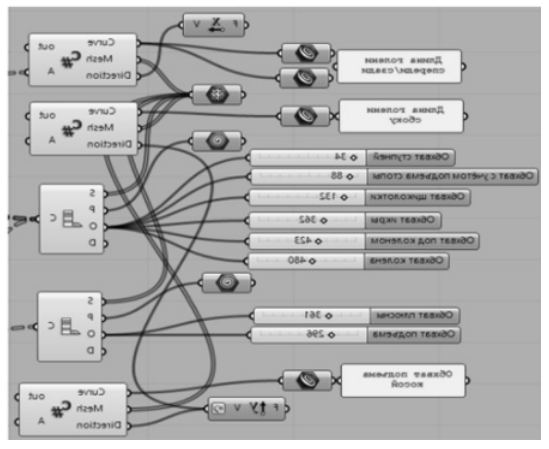

B

Рис. 4. Этапы визуализации скан-образа ног в САПР CAПP Rhinoceros 3D: a - этап сканирования субъекта; б - аватар ног; в - фрагмент нода плагина Grasshopper

Многие современные потребители с травмами ног стараются минимизировать длительность этапа ограничения двигательной активности и в соответствии с рекомендациями программ реабилитации на ранних стадиях восстановительного периода интегрируются в социум. Таким субъектам требуются персонифицированные чехлы, которые не только защищают травмированную конечность, но и гармонизируют внешний облик, скрывая непривлекательность установлен- 
М.А. Гусева и др. Трехмерная графика параметрического проектирования цифровых двойников...

ных внешних фиксаторов. Анализ модельного ряда ассортимента реабилитационных швейных изделий для ног показал, что на рынке распространены унифицированные изделия типового дизайна [9]. Прогрессивная стратегия кастомизации предполагает проектирование инновационных моделей швейных изделий при участии заказчиков продукта. Такую коммуникацию обеспечивает модуль визуализации объектов проектирования, например CAПP CLO3D. Общий формат файлов (.obj) для выбранных в проекте графических редакторов позволил экспортировать параметризированный клон ног в среду CLO3D из Rhinoceros 3D. Tрехмерный образ персонифицированного аватара ноги является основой для формирования оболочки модели реабилитационного чехла с последующей визуализацией дизайна.

На начальном этапе проектирования в CAПР CLO3D инструментами программы позиционированы направляющие плоскости, соответствующие расположению колец, полуколец и дуг аппарата Илизарова (рис. 5а). Габариты опорных колец клона-фиксатора изменяются по размерам натурного внешнего фиксатора (рис. 5б). В соответствии с пожеланиями клиента (степень прилегания изделия, параметры конфекцион-пакета и т.п.) проектировщик осуществляет выбор проекционных прибавок на основных уровнях трехмерного объекта и формирует оболочку реабилитационного чехла (рис. 5в). В качестве экспериментальной модели выполнено проектирование трехмерного изделия антропометрической конфигурации [20]. Универсальность выбранной модели определяют ее составные части (донышко, стенка, голенище), а разъемность и наличие кулисок по верхнем краю и на участке щиколоток обеспечивают удобство эксплуатации изделия (рис. 5г).

Визуализация в CAПP CLO3D модельного решения швейного чехла на аппарат Илизарова в виде цифрового клона достаточно информативна. Во-первых, образ изделия формируется на основе 3D скан-копии ног потребителя, что обеспечивает чехлу размерное соответствие. Во-вторых, инструментарий программы позволяет изменять габариты и дизайн модели. В-третьих, по согласованию с клиентом конструктор предприятия в короткие сроки модифицирует базовую модель, генерируя образ изделия в режиме онлайн (рис. 5д).

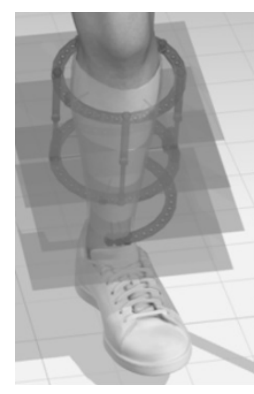

a

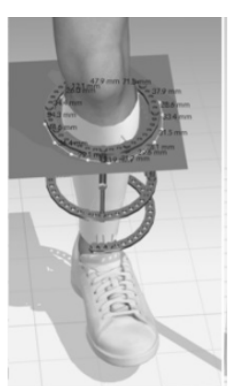

6

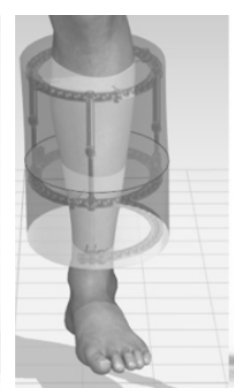

B

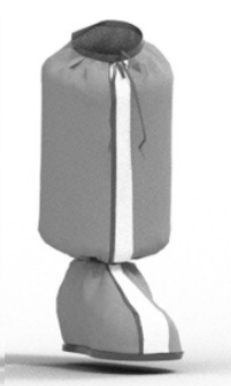

$\Gamma$

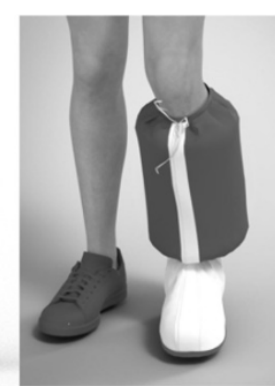

д

Рис. 5. Этапы визуализации образа чехла на внешний фиксатор в CAПP CLO3D:

a - позиционирование опорных плоскостей относительно аватара ноги;

б - корректировка размеров колец фиксатора; в - оболочка изделия на участке колец; г - базовая модель; д - визуализация посадки изделия на аватаре 


\section{Заключение}

Проведенные исследования показали востребованность инновационных швейных изделий - чехлов на аппараты внешней фиксации. Тестирование возможностей современных графических редакторов Rhinoceros 3D и CLO3D показало их совместимость и перспективность применения выбранной комбинации программ для процесса проектирования реабилитационных изделий. В условиях кастомизированного производства персонификация композиционноконструктивного решения моделей чехлов для ног выполняется поэтапно: от корректировки антропоморфных параметров до изменения дизайна в соответствии с пожеланиями клиента швейной фирмы. Визуализация образа чехла на аппарат внешней фиксации в CAПP CLO3D является оптимальным коммуникативным инструментом, не вызывающим негативных ассоциаций у потребителей. Интерактивный режим взаимодействия сотрудников предприятия и заказчиков позволяет получить персонифицированный продукт желаемого качества с высокими эргономическими и эстетическими свойствами.

1. Федеральная служба государственной статистики: [сайт]. - URL: https://rosstat.gov.ru/folder/13721 (дата обращения: 28.10.2021).

2. Петрова Е. Ю., Пахомова М. А. Психологическая реабилитация пациентов с последствиями физической травмы методом восстановления микродвигательных реакций // Клиническая психология. - 2016. - Т. 7, вып. 3. - С. 136-146.

3. Ничипоренко Н. П. Система стабилизации личности как фактор этиологии психосоматического процесса совладания с болезнью // Практическая медицина. - 2015. № 5 (90). - C. 46-50.

4. Designing functional clothes for persons with locomotor disabilities / A. Curteza, V. Cretu, L. Macovei, M. Poboroniuc // Autex Research Journal. - 2014. - Vol. 14, no. 4. - P. 281289.

5. Kabel A., Dimka J., McBee-Black K. Clothing-related barriers experienced by people with mobility disabilities and impairments // Applied Ergonomics. - 2017. - Vol. 59, Is.A. - P. $165-169$.

6. Ayachit S., Thakur M. Functional clothing for the differently abled// Indian Journal of Public Health Research and Development. - 2017. - Vol. 8, no. 4. - P. 904.

7. Расширение ассортимента товаров реабилитационной индустрии для инклюзии маломобильных граждан в социальную среду / И.Д. Гусев, М. А. Гусева, Е.Г. Андреева [и др.] // Вестник молодых ученых Санкт-Петербургского государственного университета технологии и дизайна. - 2018. - № 3. - С. 474-481.

8. Теория экстрабилити. Белая Трость URL: http://extrability.org/home/ materials/multimobility-in-employment/theory-of-extrability/ (дата обращения: 11.11.2018).

9. Свидетельство о регистрации базы данных № 2020620375 RUS. Параметрическое проектирование реабилитационных изделий / Гусев И.Д., Разин И.Б., Гусева М.А. [и др.]: заявл. 12.02.2020; опубл. 28.02.2020, Бюл. № 3.

10. ОТТОВОСК: [сайт]. - URL: https://www.ottobock.ru/orthotics/solution-overview-jointscatalogue/ (дата обращения: 28.08.2019).

11. GPC Medical LTD: Аппарат Илизарова: [сайт].- URL: https://www.indianorthopedic.ru/apparat-ilizarova/apparat-ilizarova.html (дата обращения: 28.08.2019).

12. АРСАНА: [сайт]. - URL: https://arsana-med.com/shop/ (дата обращения: 28.09.2021). 
13. Патент на полезную модель № 188409 RUS. Межсезонный чехол с подошвой на аппарат внешней фиксации / Леонтьева Л. В., Московенкова Е. Н., Леонтьев А. Н.; заявл. 08.01.2019; опубл. 11.04.2019.

14. Систематизация входной информации для проектирования швейных изделий со специальными свойствами / М. А. Гусева, В.В.Гетманцева, Е.Г. Андреева [и др.] // Территория новых возможностей. Вестник Владивостокского государственного университета экономики и сервиса. - 2018. - Т. 10, № 4. - С. 112-121.

15. Свидетельство о регистрации базы данных № 2019622196 RUS. База данных цифровых двойников сканированных полноростовых мужских фигур / Жукова И.В., Кузьмичев В.Е., Румянцев Е.В.: зарег. 27.11.2019, Бюл. № 12.

16. Карабанова Н.Ю., Сурженко Е.Я. Преимущества использования трехмерного проектирования при разработке плечевой одежды для инвалидов// Известия вузов. Технология легкой промышленности. - 2014. - Т. 23, № 1. - С. 53-57.

17. Параметризация виртуального проектирования реабилитационных изделий антропометрической формы / М. А. Гусева, Е. Г. Андреева, И. А. Петросова [и др.] // Дизайн и технологии. -2019 . - № 74 (116). - С. 39-47.

18. Цифровизация в инклюзивной антропометрии / М. А. Гусев, В. В. Костылева, И. А. Петросова [и др.] // Известия высших учебных заведений. Технология текстильной промышленности. - Иваново: ИвГПУ, 2020. - № 6. - С. 154-161.

19. Гусев И. Д., Разин И.Б. Параметрическое $3 \mathrm{~d}$ проектирование простых форм цифровых двойников швейных изделий для ног // Вестник молодых ученых СанктПетербургского университета технологии и дизайна. -2020 . - № 1. - С. 53-57.

20. Патент на полезную модель № 166649 RUS. Мешок для ног для людей с ограниченными двигательными возможностями / Гусева М.А., Андреева Е.Г., Клочкова О.В., Гусев И.Д.; заявл. 08.06.2016; опубл. 10.12.2016.

\section{Транслитерация}

1. Federal'naya sluzhba gosudarstvennoj statistiki: [sajt]. - URL: https://rosstat.gov.ru/folder/13721 (data obrashcheniya: 28.10.2021).

2. Petrova E.Yu., Pahomova M.A. Psihologicheskaya reabilitaciya pacientov s posledstviyami fizicheskoj travmy metodom vosstanovleniya mikrodvigatel'nyh reakcij // Klinicheskaya psihologiya. - 2016. - T. 7, vyp. 3. - S. 136-146.

3. Nichiporenko N.P. Sistema stabilizacii lichnosti kak faktor etiologii psihosomaticheskogo processa sovladaniya s bolezn'yu // Prakticheskaya medicina. - 2015. - № 5 (90). - S. 4650.

4. Rasshirenie assortimenta tovarov reabilitacionnoj industrii dlya inklyuzii malomobil'nyh grazhdan v social'nuyu sredu / I.D. Gusev, M. A. Guseva, E. G. Andreeva [i dr.] // Vestnik molodyh uchenyh Sankt-Peterburgskogo gosudarstvennogo universiteta tekhnologii i dizajna. - 2018. - № 3. - S. 474-481.

5. Teoriya ekstrabiliti. Belaya Trost' URL: http://extrability.org/home/ materials/multimobility-in-employment/theory-of-extrability/ (data obrashcheniya: 11.11.2018).

6. Cvidetel'stvo o registracii bazy dannyh № 2020620375 RUS. Parametricheskoe proektirovanie reabilitacionnyh izdelij / Gusev I. D., Razin I. B., Guseva M. A. [i dr.]: zayavl. 12.02.2020; opubl. 28.02.2020, Byul. № 3 .

7. ARSANA: [sajt]. - URL: https://arsana-med.com/shop/ (data obrashcheniya: 28.09.2021).

8. Patent na poleznuyu model' № 188409 RUS. Mezhsezonnyj chekhol s podoshvoj na apparat vneshnej fiksacii / Leont'eva L. V., Moskovenkova E. N., Leont'ev A. N.; zayavl. 08.01.2019; opubl. 11.04.2019. 
9. Sistematizaciya vhodnoj informacii dlya proektirovaniya shvejnyh izdelij so special'nymi svojstvami / M. A. Guseva, V. V. Getmanceva, E. G. Andreeva [i dr.] // Territoriya novyh vozmozhnostej. Vestnik Vladivostokskogo gosudarstvennogo universiteta ekonomiki i servisa. - 2018. - T. 10, № 4. - S. 112-121.

10. Svidetel'stvo o registracii bazy dannyh № 2019622196 RUS. Baza dannyh cifrovyh dvojnikov skanirovannyh polnorostovyh muzhskih figur / Zhukova I. V., Kuz'michev V.E., Rumyancev E. V.: zareg. 27.11.2019, Byul. № 12.

11. Karabanova N. Yu., Surzhenko E. Ya. Preimushchestva ispol'zovaniya trekhmernogo proektirovaniya pri razrabotke plechevoj odezhdy dlya invalidov// Izvestiya vuzov. Tekhnologiya legkoj promyshlennosti. - 2014. - T. 23, № 1. - S. 53-57.

12. Parametrizaciya virtual'nogo proektirovaniya reabilitacionnyh izdelij antropometricheskoj formy / M. A. Guseva, E. G. Andreeva, I. A. Petrosova [i dr.] // Dizajn i tekhnologii. 2019. - № 74 (116). - S. 39-47.

13. Cifrovizaciya v inklyuzivnoj antropometrii / M. A. Gusev, V.V. Kostyleva, I. A. Petrosova [i dr.] // Izvestiya vysshih uchebnyh zavedenij. Tekhnologiya tekstil'noj promyshlennosti. - Ivanovo: IvGPU, 2020. - № 6. - S. 154-161.

14. Gusev I. D., Razin I. B. Parametricheskoe 3d proektirovanie prostyh form cifrovyh dvojnikov shvejnyh izdelij dlya nog // Vestnik molodyh uchenyh Sankt-Peterburgskogo universiteta tekhnologii i dizajna. - 2020. - № 1. - S. 53-57.

15. Patent na poleznuyu model' № 166649 RUS. Meshok dlya nog dlya lyudej s ogranichennymi dvigatel'nymi vozmozhnostyami / Guseva M. A., Andreeva E. G., Kloch kova O.V., Gusev I.D.; zayavl. 08.06.2016; opubl. 10.12.2016.

(C) М.А. Гусева, 2021

(C) Е.Г. Андреева, 2021

(С) И.Б. Разин, 2021

(С) И.Д. Гусев, 2021

Для цитирования: Гусева М.А., Андреева Е.Г., Разин И.Б., Гусев И.Д. Трехмерная графика параметрического проектирования цифровых двойников швейных изделий простых форм // Территория новых возможностей. Вестник Владивостокского государственного университета экономики и сервиса. - 2021. - Т. 13, № 4. - С. 167-176.

For citation: Guseva M.A., Andreeva E.G., Razin I.B., Gusev I.D. Three-dimensional graphics of parametric design of digital twins of garments of simple shapes, The Territory of New Opportunities. The Herald of Vladivostok State University of Economics and Service, 2021, Vol. 13, № 3, pp. 167-176.

DOI https://doi.org/10.24866/VVSU/2073-3984/2021-4/167-176

Дата поступления: 08.11 .2021
Одобрена после рецензирования: 09.11 .2021
Принята к публикации: 15.11.2021 